\title{
UNA NOTA SOBRE LA ASTROLOGÍA EN LOS INICIOS DE LA POESÍA DE CANCIONERO
}

\author{
SANDRa Teresa Álvarez Ledo \\ Universidad de Vigo
}

\section{Resumen}

Este artículo expone una reflexión acerca de la huella que la astrología ha dejado en las composiciones del Cancionero de Baena, centrándose, para ello, en la obra de uno de los autores de la colectánea que mayor afición muestra hacia la referida disciplina: Ferrán Manuel de Lando. Tras llevar a cabo un balance general de la influencia de la ciencia de los astros en el conjunto de la obra del poeta, se procede al análisis pormenorizado de los tecnicismos específicos de este ámbito que se localizan en una de las composiciones más astrológicas del autor. El uso que Lando realiza de estos términos en el poema analizado, así como la presencia de una perspectiva astrológica en algunos de sus textos, con independencia de su temática, evidencia el relieve de la astrología en el conjunto de la producción del sevillano.

Palabras-clave: astrología, Lando, Cancionero de Baena, léxico astrológico, ciencia.

\section{Abstract}

This article exposes a reflection on the influence that astrology has left on the poetry of the Cancionero de Baena. For this purpose, it focuses Ferrán Manuel de Lando's works, given that he is one of the authors of the antology that shows more interest in this discipline. After offering a general view of the presence

Recibido: 16-02-2014 / Aceptado: 24-03-2014 
of astrology in the whole work of the poet, it develops a detailed analysis of the specific scientific terms that are located on the most astrological composition by the author. The use of these terms in the poem analyzed, as well as the adoption of an astrological perspective in some of his texts, regardless of their topics, shows the relief of astrology within the sevillian's poetry.

KeYwords: astrology, Lando, Cancionero de Baena, astrological vocabulary, science.

Los poetas del Cancionero de Baena (PN1) muestran, en general, una apetencia hacia los temas científicos del panorama medieval y, en particular, hacia la astrología. Para explicar la presencia de este rasgo en la literatura del momento, así como las posibilidades con las que contaron los autores legos para aproximarse a los fundamentos de esta disciplina, es importante tener en cuenta que la astrología y la astronomía gozaban de un gran interés popular. ${ }^{1}$ Esta popularidad facilitó su divulgación, convirtiéndose en un saber accesible a otros grupos de la sociedad y no solo a las élites clericales o al entorno estrictamente universitario. ${ }^{2}$

Por otra parte, el clima intelectual de la corte favorecía también la familiaridad de los poetas con las diversas materias del ámbito sapiencial, pues en la primera mitad del siglo XV se produce un resurgimiento de las traducciones que va a promover la difusión de obras y compendios sapienciales. ${ }^{3}$ Son diversas las fuentes que pudieron servir a los autores de la antología baenense como punto de partida para conocer e incorporar elementos astrológicos a sus creaciones poéticas. Los fundamentos de la astrología se difunden en la Edad Media por medio de los escritos escolásticos en torno a las principales obras aristotélicas (De caelo, Physica, Metaphysica, Meteora), a través de los comentarios del tratado de Sacrobosco (De spera), de las Sentencias de Pedro Lombardo y gracias a los textos enciclopédicos como De proprietatibus rerum de Anglicus o Speculum naturale de Beauvais. ${ }^{4}$ Los propios poetas dejan constancia del conocimiento de estas fuentes al citarlas expresamente en algunas de sus composiciones. ${ }^{5}$

1 E. B. Place, «The Exaggerated Reputation of Francisco Imperial», Speculum, 21 (1946a), pp. 467-468.

2 J. P. Boudet, Entre science et nigromance. Astrologie, divination et magie dans l'Occident médiéval (XII ${ }^{e}-X V^{e}$ siècle), Paris, Publications de la Sorbonne, 2006, p. 157.

3 F. Gómez Redondo, Historia de la prosa medieval castellana, Madrid, Cátedra, 2002, vol. 3, pp. 2112 y siguientes.

4 E. Grant, «Astronomy, Cosmology and Cosmography», Medieval Latin: an Introduction and Bibliographical Guide, F. A. C. Mantello y A. G. Rigg (eds.), Washington, The Catholic University Press, 1996, p. 363.

5 Es el caso de Fray Diego de Valencia y Juan Alfonso de Baena, quienes citan ocasionalmente obras alfonsíes, aristotélicas y averroístas (ID1606, PN1-481, «Nicolás amigo, pregunta onesta», vv. 16, 17 e ID0285, MH1-586, «Para Rey tan exçelente», v. 133, respectivamente). Para citar los versos del Cancionero de Baena, sigo la edición de Dutton y González Cuenca (Cancionero de Juan Alfonso de Baena, Madrid, Visor Libros, 1993). 
Son muy significativos los ejemplos de textos en que los autores de la colectánea baenense introducen conceptos inspirados en esta ciencia o, incluso, debaten sobre algún problema relacionado con su ámbito de estudio. Entre este último grupo destacan los poemas que abordan el tema de la fortuna, ${ }^{6}$ pues al plantear dudas en torno al azar y al determinismo como fuerzas que condicionan el destino humano, se propician, inevitablemente, las conexiones con los fundamentos de la astrología medieval. A modo de ejemplo, podrían citarse los intercambios entre Villasandino, Fray Diego, Nicolás de Valencia, Imperial y Fray Lope del Monte, entre otros. ${ }^{7}$

Esta tendencia generalizada en los poetas del contexto literario que ilustra el compendio de Juan Alfonso, tiene en el sevillano Ferrán Manuel de Lando uno de sus más fieles representantes. Existe en este autor una especial inclinación hacia la astrología, a pesar de que la variedad temática sea uno de los rasgos que caracterizan su obra, conservada fundamentalmente en el Cancionero de Baena (PN1). Aun destacándose entre sus piezas notables ejemplos que sirven al autor para experimentar con la poesía amatoria, burlesca, moralizante, religiosa, circunstancial e, incluso, teológica, se advierte en el poeta una especial afición hacia los contenidos relacionados con el ámbito de la astrología. Un privilegiado testimonio del particular relieve de esta disciplina en su poesía es la elaboración de una pregunta general en la que invita a los miembros de la corte, religiosos y laicos, a disertar sobre cuestiones astrológicas.

Pero aunque el tema solo se aborde directamente en uno de los textos conservados, la disciplina deja una huella profunda en el modo en que el autor trata otros tópicos fundamentales. Puede decirse que hay en Lando una presencia indudable de la perspectiva astrológica en su acercamiento a contenidos esenciales de la literatura del XV, como el amor, la gracia o la fortuna. Al desarrollar estos temas, el

\footnotetext{
${ }_{6}$ El tema de la fortuna comprende una amplia bibliografía, de la que recojo tan solo algunos trabajos clásicos centrados en el desarrollo de este tópico en el Cancionero de Baena: P. Le Gentil, La poésie espagnole et portugaise à la fin du Moyen Âge, Genève-Paris, Slatkine, 1981, vol. 1, pp. 351-356; J. de D. Mendoza Negrillo, Fortuna y providencia en la Literatura Castellana del siglo XV, Anejos del Boletín de la Real Academia Española, 27, 1973; E. Hoyos, Temas y tópicos en el Cancionero de Baena, Kentucky, Universidad de Kentucky, 1969 (facsímil en Michigan, UMI Dissertation Services, 1999), pp. 121-125; C. Potvin, Illusion et pouvoir (La poétique du Cancionero de Baena), Cahiers d’Études Médiévales, 9 (1989), pp. 118-128.

7 Fray Diego interroga a Villasandino sobre las relaciones entre naturaleza y fortuna en ID1598, PN1473, «Señor muy enviso e sabio cortés» (acerca de este debate: Ch. F. Fraker, «The Theme of Predestination in the Cancionero de Baena», Bulletin of Spanish Studies, 51, 1974, pp. 230-233); el mismo autor propone a Nicolás de Valencia un dilema en torno a la injusticia del destino en ID1602, PN1-477, «Leal entençión, Niculás amigo»; Imperial debate sobre la injusta fortuna con Fray Alfonso de la Monja de ID0531, PN1-245, «jOh Fortuna! çedo prive» a ID1380, PN1-246, «En ditado apuesto, muy imperial» (de este intercambio se ha ocupado C. Zilli en «Dibattito sulla Fortuna nel Cancionero de Baena?», La Nuova Ricerca, 3.3 (1994), pp. 1-50).
} 
poeta apela a la astrología para ofrecer una explicación satisfactoria de las ideas que postula; por ejemplo, en el caso del amor, un influjo planetario nocivo es el origen de sus desventuras, de manera que un cambio en el curso de los astros podría poner remedio a su dolor. En concreto, la indiferencia de la amada tiene su origen en la influencia del planeta Marte, no en la consabida crueldad femenina, de manera que la acción de Venus sobre la mujer podría cambiar sus sentimientos en beneficio del poeta:
Aquesta águila encantada,
[...]
por Mares está trabada;
mas si Venus, la temprada,
se moviesse aquí mediante,
la causa más discordante
sería bien concordada. ${ }^{8}$

Alnoconservar más muestras de la poesía amatoria del autor que, probablemente, debió componer, resulta inviable determinar si este componente astrológico alcanzó un mayor protagonismo en sus creaciones de contenido amoroso. ${ }^{9}$ Sí cabe señalar que la importancia del influjo planetario en la modificación de las inclinaciones afectivas de los amantes, simbolizado en las deidades paganas del amor, constituye un elemento con tradición literaria que el poeta parece haber heredado de Boccaccio. ${ }^{10}$

En otro contexto, al discutir sobre la gracia en un debate con Fray Lope, el planeta Venus se convierte en el instrumento divino para transmitir los dones poéticos:
Entiendo yo, simple, atar mi cabestro
al çielo muy claro de Venus planeta,
e luego emproviso por vía secreta
seré proveído del alto Saturno,
çessando los tiempos del tiempo noturno
en que faga agora reino mi cometa. ${ }^{11}$

\footnotetext{
8 Así lo expone en ID1403, PN1-269, «En rica muda de çera». En torno a los tópicos generales en la concepción de la dama y el galán: P. Le Gentil, La poésie espagnole et portugaise [...], op. cit., vol. 1, pp. 97160 y A. Ma Rodado Ruiz, «Tristura conmigo va». Fundamentos de Amor Cortés, Cuenca, Universidad de Castilla-La Mancha, 2000.

9 Acerca de la obra de Ferrán Manuel de Lando y la transmisión textual de la misma, remito a S. Álvarez Ledo, La obra poética de Ferrán Manuel de Lando, Madrid, FUE, 2012, pp. 13-27.

10 En concreto, del Filócolo. Cátedra constata, atendiendo al debate teológico que el poeta mantiene con Fray Lope del Monte (de 12P, ID1406, PN1-272, «Tomando de vos como de maestro» a 12Rp1, ID1408, PN1-274, «Mucho sé menos de quanto demuestro»), que Lando pudo conocer esta obra de Boccaccio (Amor y pedagogía en la Edad Media, Salamanca, Universidad de Salamanca, 1989, p. 82). Se documenta la presencia peninsular de obras de Boccaccio en los siglos XIV y XV, dato que podría reforzar esta hipótesis (véase al respecto: C. Alvar, «Boccaccio en Castilla: entre recepción y traducción», Cuadernos de Filología Italiana, vol. extraordinario (2001), pp. 333-334).

11 ID1406, PN1-272, «Tomando de vos como de maestro», vv. 3-8 e ID1408, PN1-274, «Mucho sé menos de quanto demuestro», vv. 9-16. Otro ejemplo de los vínculos entre influencia planetaria y gracia poética se ofrece en ID1499, PN1-374, «En sino esforçado e muy abundante», vv. 1 y 2.
} 
También en relación con este tópico, cuando elabora el panegírico de Fray Vicente afirma que su virtud para convertir a los pecadores radica en la influencia planetaria especialmente benigna con la que Dios ha querido agraciarlo:
Su firme planeta assí nos enclina que luego en punto a Dios nos tornamos. por ende, señores, sin dubda creamos que bive alumbrado de gracia divina. ${ }^{12}$

Como consecuencia de este enfoque, entre los elementos clave de su modo de hacer poético, destacan los conceptos, las metáforas y los símiles basados en el uso de la astrología. Este rasgo puede ilustrarse con los siguientes textos: en ID0456, PN1277, aborda el problema de los inconvenientes de la ambición excesiva para ofrecer un consejo moralizante a su prima Inés de Torres, desterrada de la corte en 1416. La imagen que emplea para plasmar los cambios del destino personalizados en la Fortuna es la de la radiación o inflamaçión astral («Pues que Fortuna sus rayos inflama / e buelve la rueda del mundo mudable», vv. 1 y 2). A su vez, la gracia poética se describe como una influençia de Venus en ID1418, PN1-285, «Filósofo palançiano», vv. 1-4, panegírico dirigido al rey:

Filósofo palançiano, varón de alta prudençia, a quien dio rica influençia el grand planeta diafano.

La gracia poética es un tema esencial en la obra conservada de Lando, especialmente en los debates que mantiene para medir su calidad artística contra hábiles poetas como Villasandino y Baena. ${ }^{13}$ En algunos de estos encuentros la gracia infusa se presenta como un don divino, sin hacer explícita connotación astrológica alguna, aunque en muchas ocasiones, el don del Creador se pone en relación con la fortuna, entendida como potencia astrológica subordinada a la divinidad:

$$
\begin{aligned}
& \text { Que yo vos daré inforismo } \\
& \text { de razón sotil alguna, } \\
& \text { sin tomar regla ninguna } \\
& \text { de maestro nin doctor, } \\
& \text { salvo graçia del Señor } \\
& \text { que reina sobre Fortuna. }{ }^{14}
\end{aligned}
$$

\footnotetext{
12 ID1419, PN1-287, «Señores, miremos el noble doctor», vv. 61-64. La gracia poética es un tema esencial en la obra conservada de Lando, especialmente en los debates que mantiene para medir su calidad artística contra hábiles poetas, como Villasandino y Baena. En algunos de estos encuentros la gracia infusa se presenta como un don divino, sin hacer explícita connotación astrológica alguna, aunque en muchas ocasiones, el don del Creador se pone en relación con la fortuna, entendida como potencia astrológica subordinada a la divinidad.

13 Sobre el relieve de este tópico en la poesía del autor: S. Álvarez Ledo, La obra poética de Ferrán Manuel de Lando, op. cit., pp. 28-29.

14 ID0514, PN1-257, «Alfonso Álvarez, amigo», vv. 51-56. Otros ejemplos de estos usos pueden ver-
} 
Fuera dela obra del propio Lando, ha sobrevivido también una importante prueba de sus intereses astrológicos: se trata del testimonio de uno de sus contemporáneos, a la par que rival poético: Fray Lope del Monte. El religioso, al disputar con el sevillano en torno a la gracia alude, no sin cierta ironía, a las aficiones astrológicas de Lando y pone a prueba su dominio de la materia, planteándole algunas interpretaciones basadas en el conocimiento de los influjos planetarios. ${ }^{15}$

Al contrario que otros poetas de su entorno, Ferrán Manuel no manifiesta reticencias en torno a la moralidad de la astrología, manejando sus tecnicismos y planteando sus problemas de forma abierta. De todos modos, el interés y la apertura de Lando hacia la astrología no le impiden desarrollar una mirada crítica ante la misma, suscribiendo, como consecuencia, una clásica distinción realizada por la ortodoxia teológica de su tiempo, conforme a la que conviene separar el conocimiento astronómico de la astrología judiciaria y otras prácticas esotéricas. Este rechazo, arraigado, al menos teóricamente, en el pensamiento castellano, ${ }^{16}$ es expresado por el autor de forma explícita en una de sus composiciones: el panegírico a Fray Vicente Ferrer, donde expone su condena de las artes adivinatorias al encomiar la labor del fraile combatiendo la superstición:

Condena e estruye las artes dañosas

de los adevinos e falsos profetas, mostrando que sinos, cursos, planetas, a Dios obedeçen en todas las cosas. ${ }^{17}$

A la hora de hacer balance de la destreza con que el autor maneja la disciplina, puede afirmarse que exhibe un dominio de los tecnicismos y principios fundamentales de esta ciencia, demostrando que, aun careciendo de instrucción reglada, supo aprender los rudimentos de la astrología a través del autodidactismo. Tanto Lando como otros poetas del Cancionero de Baena han sido acusados de superficialidad en su manera de

se en ID1394, PN1-260, vv. 21-30; ID1397, PN1-264, vv. 45-50. Fuera del marco de la disputa, pero en un contexto de diálogo poético, este tratamiento deja también testimonio como se advierte en ID1409, PN1-275, vv. 5-8, texto en el que Lando pide consejo a Cañizares para superar una crisis de creatividad: «maguer en quanto Dios quiso / fize algunas simples obras / Fortuna con sus çoçobras / ya del todo me conquiso».

15 Se trata de ID1407, PN1-273, «Loando al Señor, Redemidor nuestro», v. 10.

16 L. M., Vicente García, «La astrología en el Libro de Buen Amor. Fuentes y problemas sobre el uso de conceptos astrológicos en la literatura medieval española», Revista de Literatura, 122, 1999, pp. 333-339; del mismo autor: Estrellas y astrólogos en la literatura medieval española, Madrid, Ediciones del Laberinto, 2006, pp. 94-107. L. M. Vicente García, «La astrología en el Libro de Buen Amor [...]», art. cit., pp. 333-339; L. M. Vicente García, Estrellas y astrólogos..., op. cit., pp. 94-107.

17 ID1419, PN1-287, «Señores, miremos el noble doctor», vv. 37-40. Otro ejemplo del rechazo de la superstición por parte del autor puede leerse en ID1408, PN1-274, «Mucho sé menos de quanto demuestro», v. 36, donde ataca a «los que catan en sus estornudos». 
aproximarse a problemas científicos, ${ }^{18}$ pero antes de considerar que la ignorancia es la causa de tal circunstancia conviene tener en cuenta la naturaleza de las obras que componen, sujetas a unas estrictas normas retóricas y encaminadas prioritariamente, no a la especulación científica, sino a la demostración de la maestría y de la agudeza artística.

Partiendo de estas observaciones preliminares y con el fin de valorar la importancia de la astrología en la obra de Ferrán Manuel, resulta conveniente abordar con mayor detenimiento el análisis del decir número ID1402, PN1-268, «A todos los sabios poetas seglares». Esta propuesta de debate especializada en contenidos astrológicos sirve al autor para plantear varias cuestiones sobre el orden cósmico, el movimiento planetario, la teoría de las conjunciones y la Fortuna, entendida como potencia cosmológica. Dado que algunas de estas preguntas son problemas teóricos que formaban parte de los programas de estudio y tratados producidos en el entorno universitario, ${ }^{19}$ esta pieza no solo es un buen ejemplo de los intereses astrológicos del poeta, sino también una prueba de su destreza en el manejo de disputas de inspiración científica. De hecho, en el verso 34, el propio autor emplea para designar su demanda un término procedente de las metodologías didácticas de la universidad medieval (liçión), con el fin de destacar el valor científico de su propuesta. ${ }^{20}$

Puesto que Ferrán Manuel quiere propiciar con este texto un gran debate en la corte, se dirige a un destinatario general y reduce al máximo el espacio dedicado a las fórmulas retóricas salutatorias, sintetizando todos estos elementos en los cuatro versos iniciales.

En cuanto a las demandas son seis y se disponen del siguiente modo: en la primera copla se interroga sobre los movimientos de los cuerpos celestes y del cielo zodíaco (vv. 5-8); en la segunda se insertan dos preguntas, una en torno a la sustentación de la tierra (vv. 9-12), la otra, sobre la música de las esferas celestes (vv. 13-16); la tercera estrofa se especializa en cuestiones relativas a la Fortuna como cuál es su casa (v. 17), qué complexión tiene (v. 18), cuál es la frecuencia de sus movimientos (v. 19), si toma algún alimento (v. 20) y, finalmente, cuál es su apariencia (v. 21); en la

18 Ch. F. Fraker, Studies on the Cancionero de Baena, op. cit., p. 120; E. Hoyos, Temas y tópicos en el Cancionero de Baena, op. cit., p. 37.

19 B. Lawn, The Salernitan Questions. An Introduction to the History of Medieval and Renaissance Problem Literature, Oxford, Clarendon Press, 1963, pp. 40 y siguientes.

${ }^{20}$ Junto a la disputa y el sermón, la lección constituye una de las técnicas de enseñanza canónicas en la universidad medieval; consistía en el desarrollo de la glosa de un texto por parte del maestro, mientras que los estudiantes se limitaban a escuchar sus puntualizaciones sobre el mismo (P. Glorieux, «L'enseignement au moyen âge. Techniques et méthodes en usage à la Faculté de Theólogie de Paris, au XIII ${ }^{e}$ siècle», Archives d'histoire doctrinale et littéraire du Moyen Age, É. Gilson et alii (dirs.), Paris, Librairie Philosophique J. Vrin, 1969, pp. 108-109). 
cuarta interroga en torno a las radiaciones de Saturno y Marte (vv. 28-29); por último, en los versos 30-32 plantea el problema de las conjunciones. La finida cumple un papel fundamental en este intercambio, al consignar el plazo para presentar las réplicas. ${ }^{21}$ En consonancia con el tono astrológico del texto, este límite temporal se expresa con tecnicismos científicos propios de la disciplina.

Si bien los contenidos del poema dan testimonio suficiente del vínculo entre este texto y la ciencia de los astros, los abundantes tecnicismos y conceptos manejados por Ferrán Manuel para plantear las cuestiones del debate refuerzan el nexo. Entre estos elementos cabe destacar, por su uso claramente especializado, los que siguen:

Luminares (v. 5): el término designa a las estrellas en general, de acuerdo con Alfonso de Palencia, mientras que la voz luminarias se aplica al Sol y a la Luna. ${ }^{22}$ Lando ya ha citado a las estrellas en el verso anterior, por lo que es probable que utilice este sustantivo para referirse estrictamente al Sol y a la Luna; se trataría de una licencia requerida para adaptar a la rima el tecnicismo, procedimiento bastante frecuente en la poesía del sevillano. Este uso pone de manifiesto que, a pesar de las pretensiones científicas del debate y de sus innegables vínculos con una ciencia de la época, la naturaleza poética del texto, con sus normas retóricas, se impone sobre las demás facetas de la composición.

Los doze signos en çirculaçión (verso 6): el autor alude en este verso al movimiento de los signos del zodíaco, situados en el cielo estrellado o cielo zodíaco, cuyo giro se completa en un día y ejerce una importante influencia sobre los seres naturales. ${ }^{23} \mathrm{Al}$ contrario que el tecnicismo precedente, que apenas se registra en el contexto poético durante la época del autor, los doze signos suponen una referencia bastante frecuente en la poesía erudita de esta etapa. Así se evidencia en la obra de autores muy próximos a Lando, como Imperial, o algo posteriores, como Juan de Mena. ${ }^{24} \mathrm{Al}$ margen del gusto personal que, sin duda, el sevillano manifiesta hacia la astrología, la presencia de estos y otros elementos léxicos en las composiciones de autores coetáneos o próximos, manifiesta que, tales usos, vienen condicionados también por las convenciones

21 A. Chas Aguión, «Concordancias y discordancias temporales en los intercambios poéticos de cancionero: el tiempo de creación y el tiempo de ejecución», Le concordance des temps. Moyen Âge et époque moderne, G. Luquet (ed.), Paris, Presses Sorbonne Nouvelle, 2010, p. 157.

22 A. de Palencia, Universal vocabulario en latín y en romance, Sevilla, 1490 (edición facsímil en Madrid, Comisión Permanente de la Asociación de Academias de la Lengua Española, 1967, sv lumino).

23 E. de Villena, Obras completas, P. M. Cátedra (ed.), Madrid, Turner, 1994, vol. 1, pp. 533-556; Ch. Burnett, «Astrology», Medieval Latin: an Introduction and Bibliographical Guide, F. Anthony, et alii (eds.), Washington, The Catholic University Press, 1996, pp. 372-373; M. de Marco, «Tecnicismos y cultismos en el Lapidario de Alfonso X el Sabio», Hesperia: Anuario de Filología Hispánica, 7, 2004, p. 52.

24 Para estas documentaciones remito al CORDE (http:/ / www.rae.es [marzo de 2014]). 
y tendencias estilísticas propias de una estética literaria, en este caso, la del decir alegórico. ${ }^{25}$

Cuentos (verso 8): el término, que suele emplearse como sinónimo de 'números', tiene aquí el significado específico que deriva de su uso en los libros de astrología, utilizándose para referir la cantidad de las estrellas. Así se observa en Libros del saber de Astronomía de Alfonso X, donde se dedica un apartado a determinar cuál es el número (cuento) de las estrellas en cada una de las constelaciones ofiguras previamente descritas. ${ }^{26}$

Entre los versos 9 y 10, el poeta plantea el problema de la sustentaçión, es decir, el de la fuerza que sostiene el cosmos; es este un asunto teorizado en algunos tratados astrológicos coetáneos, por ejemplo, el de Villena. ${ }^{27}$ Se trata, además, de una pregunta tópica entre los temas de la poesía científica del momento, como se advierte en el debate entre Fray Diego y Nicolás de Valencia (ID1605, PN1-480, «Maestro señor, por vuestra mesura»).

En el verso 13, el poeta plantea una reflexión sobre otro elemento astrológico clásico, en concreto, la décima esfera o cielo empíreo donde, de acuerdo con la cosmología de la época, residían los bienaventurados. Este último cuerpo superior lo rodea y contiene todo, es inmóvil y no está contenido por ningún otro. Urbano IV encargó la formulación de esta teoría a Campanus de Novara, quien la recogió en la obra Theorica Planetarium. ${ }^{28}$

Al mencionar, en el verso 16 los dulçes cantares, Lando está aludiendo a la música celestial que producen las esferas en su movimiento. ${ }^{29}$ Estos sonidos son presentados 25 Así lo indica Vicente García al valorar la importancia de la astrología en la obra de Juan de Mena:
«Notas sobre la actitud de Juan de Mena hacia la astrología a propósito del libro de Sue Lewis: Astrolo-
gy and Juan de Mena's Laberinto de Fortuna», Revista de Literatura Medieval, 16, 2004, pp. 300-301.

26 Alfonso X, Libros del saber de astronomía, ff. $20^{\mathrm{v}}-25^{\mathrm{v}}$. Accesible desde el siguiente enlace: <http:/ / alfama.sim.ucm.es/dioscorides /consulta_libro.asp?ref=B19953008\&disme=0>

27 La clave de la sustentación del universo reside en la redondez: «E sabed que la natura fue próvida e muy sabia en fazer el çielo redondo, ca non ay cosa que ansí ençierre a las otras como es lo redondo [...]. $\mathrm{Et}$, por ende, convenía de fuerça que el çielo fuesse redondo e llano de dentro, en guisa que igualmente ençerrase dentro de sí todas las esperas, ansí que lo uno sustente e lo otro sea sostenido, ca sin sostenimiento non podría durar» (E. de Villena, Obras completas, ed. cit., vol. 1, pp. 425-426).

28 En torno al cielo Empíreo: P. Duhem, Le système du monde. Histoire des doctrines cosmologiques de Platon à Copernic, Paris, Hermann, 1959, vol. 10, p. 174; para una exposición detallada de la concepción del espacio, véase también, del mismo autor: Medieval Cosmology. Theories of Infinity, Place, Time, Void, and the Plurality of Worlds, R. Ariew (ed.), Chicago, Londres, The University Chicago Press, 1985, pp. 139-291. Duhem aborda por extenso en el volumen 10 de Le système du monde, la evolución experimentada a lo largo del siglo XV por las teorías sobre el espacio.

29 San Isidoro encarece la musicalidad cósmica en las Etimologías (J. González Cuenca (ed.), Las Etimologías de San Isidoro Romanceadas, Salamanca-León, Universidad de Salamanca-Consejo Superior de Investigaciones Científicas, 1983, p. 239). Al margen de la metáfora poética, existe una especial relación 
por el autor metafóricamente en el poema, gracias a su identificación con los cánticos de los bienaventurados (santos juglares, v. 13). Se trata de la música suprema que representa la culminación de todas las armonías de acuerdo con la jerarquización de las categorías musicales típicamente medieval. ${ }^{30}$

Mansión (verso 18): Lando pregunta cuál es la casa de la Fortuna o ubicación de esta fuerza en el espacio. En el verso 31 vuelve a expresar el mismo concepto empleando el tecnicismo preciso que la disciplina astrológica reserva para esta noción (casas). Se refiere a cada uno de los segmentos que se obtiene al subdividir los cuatro cuadrantes de la esfera celeste en tres partes. ${ }^{31}$ El recorrido de los planetas por las casas es vital, ya desde la Antigüedad, para determinar la influencia planetaria sobre el mundo. ${ }^{32}$ La casa de la Fortuna es la undécima de acuerdo con el Libro de las Cruces. ${ }^{33}$ No son muy abundantes los registros del término en contextos poéticos con esta acepción científica, por lo que es muy significativo destacar el uso del mismo en otro autor del compendio de Juan Alfonso que, además, fue interlocutor de Ferrán Manuel de Lando en algunos debates; se trata de Fray Lope del Monte, quien hace uso del referido tecnicismo en ID1474, PN1-348, «Estando la Ursa Mayor trastornada», v. 58. Para valorar adecuadamente la excepcionalidad de esta voz empleada por Lando, hay que tener en cuenta también que el significado astrológico que presenta en el texto no suele estar asociado a la misma; es decir, las documentaciones de mansión testimonian el uso del término bajo la connotación semántica de 'vivienda' ${ }^{34}$ Evidentemente, la necesidad de adaptarse a la rima en /-ón/ explica el recurso a este sinónimo, forma menos ortodoxa que casa para designar las ubicaciones planetarias.

Façión (verso 23): podría tratarse de una forma vulgarizada del tecnicismo facies, 'subdivisiones de los signos del zodíaco en tres partes iguales de seis grados cada

entre música y astronomía, vinculadas en tanto que disciplinas del quadrivium (sobre este particular, remito al clásico trabajo de J. P. Wickersham Crawford: «The Seven Liberal Arts», Romanic Review, 4 (1913), pp. 58-75).

30 Sobre esta cuestión: $\mathrm{M}^{a}$ V. Chico Picaza, «La teoría medieval de la música», Anales de Historia del Arte, 13 (2003), pp. 92 y ss. Martín Romero ha destacado la imagen de la música celestial como motivo de inspiración frecuente en la Edad Media, tanto en las artes plásticas como en la literatura (J. J. Martín Romero, «"El canto es deleite de los ángeles". Música y espiritualidad en el siglo XV», De lo humano y lo divino en la literatura medieval: santos, ángeles y demonios, J. Paredes (ed.), Granada, Universidad de Granada, 2012, pp. 223-233.

31 Para la definición técnica de este término véase también J. Casulleras, «Métodos para determinar las casas del horóscopo en la astronomía medieval árabe», Al-Qantara, 30 (2009), pp. 47 y ss.

32 K. von Stuckrad, Astrología. Una historia desde los inicios hasta nuestros días, Barcelona, Herder, 2005, pp. 33-34.

33 Alfonso X, Libro de las Cruces, Ll. A. Kasten y L. B. Kiddle (eds.), Madrid, Consejo Superior de Investigaciones Científicas, 1961, p. 11.

34 J. Corominas y J. A. Pascual, Diccionario Crítico Etimológico Castellano e Hispánico, Madrid, Gredos, 1980-1981, sv MANIDO, pp. 812-814. 
una, que están bajo la dominación de un planeta', ${ }^{35}$ creada por el autor para salvar la rima, como en el caso anterior. La interpretación es dudosa pues, a pesar de la analogía gráfica, resulta difícil determinar en qué sentido es aplicado por el poeta en el contexto. Lando pregunta por el móvil de las actuaciones de la fortuna (encuentros e azares, v. 24) y especula sobre los elementos constitutivos de esta fuerza que podrían tener un papel determinante en tales acciones (por ejemplo, su apariencia física, simple visión, en el verso 18). Entre esos elementos alude a la façión. Con independencia del sentido técnico preciso que el autor atribuya a esta voz en el verso, parece evidente que está jugando, además, con alguna de las acepciones más comunes de façión. El haber introducido a la potencia astrológica bajo el simbolismo de la deidad pagana propicia este juego. Significados como «rostro», asociados comúnmente a este término, permiten referirse a los elementos constitutivos de la fortuna, sobre los que pretende indagar el poeta, bajo la analogía con la divinidad pagana. ${ }^{36}$

Inflamaçión (verso 27): se refiere a la «radiación», como indican Dutton y González Cuenca; ${ }^{37}$ es decir, al influjo ejercido por los cuerpos celestes sobre el mundo terrestre por medio de la emisión de rayos. Esta teoría fue desarrollada por el astrólogo árabe Al Kindi en la obra De radiis stellarum. ${ }^{38}$ Este tecnicismo es relativamente frecuente en el contexto poético de la primera mitad del XV; así, el Cancionero de Baena ofrece interesantes ejemplos de su inserción en la obra de otros poetas próximos a Lando, como Gonzalo Martínez de Medina, caracterizado también por su cultivo de las composiciones de tono erudito y científico. ${ }^{39}$ El término parece haber gozado en el ámbito poético de mayor continuidad que otras de las voces comentadas, pues presenta documentaciones en la poesía de autores cuya labor no se circunscribe al entorno de Baena. ${ }^{40}$

35 J. P. Boudet, Entre science et nigromance..., op. cit., p. 60. Este tecnicismo se documenta también bajo la forma de raigambre árabe adurugen (D. Oliver Pérez, «Los arabismos del Libro conplido y otras huellas árabes», Anuario de lingüística Hispánica, 21-22, 2005-2006), p. 101).

36 Para esta acepción de façión remito a J. Corominas y J. A. Pascual, Diccionario Crítico Etimológico [...], op. cit., sv HACER, p. 299.

37 B. Dutton y J. González Cuenca (eds.), Cancionero de Juan Alfonso de Baena, ed. cit., p. 469.

38 K. von Stuckrad, Astrología, op. cit., p. 200.

39 Véase, por ejemplo, el texto ID1463, PN1-337, «001-22 (tro', asociados comu, " “” por 《<>> porque en las normas pone que se prefieren.

La Deidad es un ser infinido», v. 6. Para la obra de Gonzalo Martínez, véase: M. Condor Orduña, «La obra literaria de Gonzalo Martínez de Medina en el Cancionero de Baena», Revista de Literatura, 48, 1986, pp. 315-349.

40 Es el caso del marqués de Santillana, registrado en CORDE, que hace uso del tecnicismo bajo su acepción astrológica en un contexto amatorio, concretamente, en El Infierno de los enamorados: «al tiempo que muestra el polo / la gentil cara de Apolo / e dyurna inflamaçión» (copla número 11; http:/ / www. rae.es [marzo de 2014]). 
Por medio del adjetivo duras Lando alude a las connotaciones negativas que caracterizaban a los planetas Saturno y Marte en la astrología medieval. ${ }^{41}$

Anteçedente / relaçión (verso 30): el primer término designa al signo zodiacal que asciende por el horizonte oriental; el segundo, se refiere al ángulo de los planetas entre sí. ${ }^{42}$ La mayoría de las documentaciones de anteçedente durante el siglo XV se registran en contextos distintos del estrictamente astrológico, siendo empleado bajo su acepción lógico-causal en textos de naturaleza gramatical, médica o teológica. ${ }^{43}$ Este hecho destaca la especificidad del uso poético del mismo que desarrollan Lando y otros autores del Cancionero de Baena. Si bien relaçión, bajo el significado de 'relato', constituye una voz bien documentada en contextos jurídicos, poéticos y literarios, ${ }^{44}$ bajo el sentido netamente astrológico es más escasa, sobre todo en el terreno de la poesía, ámbito en el que se circunscribe nuevamente a la antología de Juan Alfonso y, en particular, a la obra de Lando.

Conjunçión (verso 31): desde una perspectiva geocéntrica, es el momento en que los planetas están juntos en el cielo. ${ }^{45}$ La teoría de las conjunciones tiene su referente teórico por excelencia en Albumasar, cuyas obras alcanzaron gran difusión en los siglos XIV y XV. ${ }^{46}$ Fuera del contexto astrológico, donde la voz está bien documentada, se registra durante la época del autor en contextos teológicos y, escasamente, en el terreno poético. ${ }^{47}$

En el verso 36, el poeta fija el plazo para las respuestas hacia el final de verano cuando «van decayendo los Caniculares»; aunque el último término pueda aplicarse, como indican Dutton y González Cuenca, a los calores del verano, ${ }^{48}$ también admite,

41 Acerca de estas cualidades: R. Llull, «Tractat d'Astronomia», Textos y estudios sobre astronomía española en el siglo XIII, J. Vernet (ed.), Barcelona, Universidad Autónoma, 1981, p. 226. En torno a las características de Saturno en la astrología medieval, remito también a Klibansky, Panofsky y Saxl, Saturno y la melancolía, Madrid, Alianza Editorial, 1991, pp. 183-198.

${ }^{42}$ K. von Stuckrad, Astrología, op. cit., pp. 31-32.

${ }_{43}$ Así se advierte a través de los registros del CORDE, que ofrece ejemplos de su presencia en el Libro de las paradojas del Alonso Fernández de Madrigal y en textos médicos, como el Tratado de cirugía Mayor de Lanfranco (http:/ / www.rae.es [marzo de 2014]). Véase también: R. J. Cuervo, Diccionario de construcción y régimen de la lengua castellana, Bogotá, Instituto Caro y Cuervo, 1886-1893 (edición facsímil: Bogotá, Instituto Caro y Cuervo, 1994), sv. ANTECEDENTE, p. 483. El único ejemplo del tecnicismo con sentido astrológico ofrecido por Cuervo procede de este poema de Ferrán Manuel.

44 J. Corominas y J. A. Pascual, Diccionario Crítico Etimológico..., op. cit., sv. PREFERIR, p. 634.

45 Ibídem, p. 31.

46 E. Garin, El zodíaco de la vida. La polémica astrológica del Trescientos al Quinientos, Barcelona, Ediciones Península, 1981, pp. 42-43.

47 Concretamente, y de acuerdo con los datos del CORDE, en los sermones de Fray Vicente Ferrer y en composiciones poéticas de Lando y Fray Diego de Valencia (http:/ / www.rae.es [marzo de 2014]).

48 B. Dutton y J. González Cuenca (eds.), Cancionero de Juan Alfonso de Baena, ed. cit., p. 469. 
de acuerdo con Alonso, una lectura en sentido más astrológico, aplicándolo a la estrella Sirio de la constelación de Can Mayor. ${ }^{49}$ Ambas interpretaciones son compatibles en el contexto, pues la época más calurosa del verano coincide con el momento del orto helíaco de Sirio, primera aparición de la estrella en el horizonte tras el período de invisibilidad. ${ }^{50}$

Tras considerar este análisis, resulta evidente la particular afinidad de la obra de Ferrán Manuel con la astrología; en el texto considerado, el autor ha querido formular un debate que se centra en el ámbito de la ciencia astrológica; es decir, esta disciplina no ha servido simplemente como un enfoque general para abordar otros problemas más específicos que podrían pertenecer a otros campos temáticos, sino que el núcleo del debate está constituido por cuestiones que forman parte del objeto de estudio específico de la astrología. Pero, además, ha sabido emplear un léxico especializado con un sentido técnico preciso, demostrando así su familiaridad con estos conocimientos.

\section{BibliografíA}

Alfonso X, Libro de las Cruces, Ll. A. Kasten y L. B. Kiddle (eds.), Madrid, Consejo Superior de Investigaciones Científicas, 1961.

Libros del saber de Astronomía. Disponible en web: <http://alfama.sim.ucm.es/ dioscorides/consulta_libro.asp?ref=B19953008\&disme=0> (Última consulta: febrero de 2014).

Alonso, M., Diccionario Medieval Español, Salamanca, Universidad Pontificia de Salamanca, 1986, 2 vols.

Alvar, C., «Boccaccio en Castilla: entre recepción y traducción», Cuadernos de Filología Italiana, vol. extraordinario (2001), pp. 333-350.

Álvarez Ledo, S., La obra poética de Ferrán Manuel de Lando, Madrid, FUE, 2012.

Boudet, J. P., Entre science et nigromance. Astrologie, divination et magie dans l'Occident médiéval (XII $-X V^{e}$ siècle), Paris, Publications de la Sorbonne, 2006.

BurnetT, Ch., «Astrology», en F. A. C. Mantello, et alii (eds.), Medieval Latin: An Introduction and Bibliographical Guide, Washington, The Catholic University Press, 1996, pp. 369-382.

CAsulleras, J., «Métodos para determinar las casas del horóscopo en la astronomía medieval árabe», Al-Qantara, 30 (2009), pp. 41-67.

\footnotetext{
49 M. Alonso, Diccionario Medieval Español, Salamanca, Universidad Pontificia de Salamanca, 1986, sv canícula.

50 J. Tester, Historia de la Astrología occidental, Madrid, Siglo Veintiuno editores, 1990, p. 18. El CORDE registra otro ejemplo del uso en contexto poético de este tecnicismo; se trata del Comentario a la Coronación del marqués de Santillana (http:/ / www.rae.es [marzo de 2014]).
} 
Cátedra, P. M., Amor y pedagogía en la Edad Media, Salamanca, Universidad de Salamanca, 1989.

Condor Orduña, M., «La obra literaria de Gonzalo Martínez de Medina en el Cancionero de Baena», Revista de Literatura, 48 (1986), pp. 315-349.

Corominas, J., y J. A. Pascual, Diccionario Crítico Etimológico Castellano e Hispánico, Madrid, Gredos, 1980-1981, 6 vols.

CRAWford, J. P. Wickersham, «The Seven Liberal Arts in the Visión Deleitable of Alfonso de la Torre», Romanic Review, 4 (1913), pp. 58-75.

Cuervo, R. J., Diccionario de construcción y régimen de la lengua castellana, Bogotá, Instituto Caro y Cuervo, 1886-1893 (edición facsímil: Bogotá, Instituto Caro y Cuervo, 1994).

Chas Aguión, A., «Concordancias y discordancias temporales en los intercambios poéticos de cancionero: el tiempo de creación y el tiempo de ejecución», en G. Luquet (ed.), Le concordance des temps. Moyen Âge et époque moderne, , Paris, Presses Sorbonne Nouvelle, 2010, pp. 153-174.

Chico PicAzA, M ${ }^{a}$ V., «La teoría medieval de la música», Anales de Historia del Arte, 13 (2003), pp. 83-95.

DuHeM, P., Le système du monde. Histoire des doctrines cosmologiques de Platon à Copernic, Paris, Hermann, 1959, vol. 10.

Medieval Cosmology. Theories of Infinity, Place, Time, Void, and the Plurality of Worlds, R. Ariew (ed.), Chicago, Londres, The University Chicago Press, 1985.

Dutton, B., Catálogo-índice de la poesía cancioneril del siglo XV, Madison, Hispanic Seminary of Medieval Studies, 1982.

y J. Krogstad (eds.), El Cancionero del Siglo XV (c. 1360-1520), Salamanca, Biblioteca Española del siglo XV, Universidad de Salamanca, 1990-91.

y J. González Cuenca (eds). Cancionero de Juan Alfonso de Baena, Madrid, Visor Libros, 1993.

Fraker, Ch. F., Studies on the Cancionero de Baena, Valencia, Artes Gráficas Soler, 1966.

, «The Theme of Predestination in the Cancionero de Baena», Bulletin of Spanish Studies, 51 (1974), pp. 228-243.

Garin, E., El zodíaco de la vida. La polémica astrológica del Trescientos al Quinientos, Barcelona, Ediciones Península, 1981.

Glorieux, P., «L'enseignement au moyen âge. Techniques et méthodes en usage à la Faculté de Theólogie de Paris, au XIII siècle», en É. Gilson et alii (dirs.), Archives d'histoire doctrinale et littéraire du Moyen Âge, Paris, Librairie Philosophique J. Vrin, 1969, pp. 65-186.

Gómez Redondo, F., Historia de la prosa medieval castellana, Madrid, Cátedra, 2002, vol. 3. 
González CuencA, J. (ed.), Las Etimologías de San Isidoro Romanceadas, Salamanca-León, Universidad de Salamanca-Consejo Superior de Investigaciones Científicas, 1983.

Grant, E., «Astronomy, Cosmology and Cosmography», en F. A. C. Mantello, et alii (eds.), Medieval Latin: an Introduction and Bibliographical Guide, , Washington, The Catholic University Press, 1996, pp. 363-368.

Hoyos, E., Temas y tópicos en el Cancionero de Baena, Kentucky, Universidad de Kentucky, 1969 (facsímil en Michigan, UMI Dissertation Services, 1999).

Klibansky, R., E. Panofsky, F. Saxl, Saturno y la melancolía, Madrid, Alianza Editorial, 1991.

LAwn, B., The Salernitan Questions. An Introduction to the History of Medieval and Renaissance Problem Literature, Oxford, Clarendon Press, 1963.

Le Gentil, P., La poésie espagnole et portugaise à la fin du Moyen Âge, Genève-Paris, Slatkine, 1981, vol. 1.

Llull, R., «Tractat d'Astronomia», en , J. Vernet (ed.), Textos y estudios sobre astronomía española en el siglo XIII, Barcelona, Universidad Autónoma, 1981.

Marco, M. de, «Tecnicismos y cultismos en el Lapidario de Alfonso X el Sabio», Hesperia: Anuario de Filología Hispánica, 7 (2004), pp. 37-56.

Martín Romero, J. J., «“El canto es deleite de los ángeles”. Música y espiritualidad en el siglo $X V »$, en J. Paredes (ed.), De lo humano y lo divino en la literatura medieval: santos, ángeles y demonios, Granada, Universidad de Granada, 2012, pp. 221246.

Mendoza Negrillo, J. de D., Fortuna y providencia en la Literatura Castellana del siglo XV, Anejos del Boletín de la Real Academia Española, 27 (1973).

Oliver Pérez, D., «Los arabismos del Libro conplido y otras huellas árabes», Anuario de lingüística Hispánica, 21-22 (2005-2006), pp. 67-118.

Palencia, A. de., Universal vocabulario en latín y en romance, Sevilla, 1490 (edición facsímil en Madrid, Comisión Permanente de la Asociación de Academias de la Lengua Española, 1967).

Place, E. B., «The Exaggerated Reputation of Francisco Imperial», Speculum, $21\left(1946^{\mathrm{a}}\right)$, pp. 457-473.

Potvin, C., Illusion et pouvoir (La poétique du Cancionero de Baena), Cahiers d'Études Médiévales, 9 (1989).

Real Academia Española, Banco de datos (CORDE) [en línea]. Corpus diacrónico del español. Disponible en: http: / / www.rae.es. (Última consulta: febrero de 2014).

Rodado Ruiz, A. M., "Tristura conmigo va»: Fundamentos de Amor Cortés, Cuenca, Universidad de Castilla-La Mancha, 2000.

STUCKRAD, K. von., Astrología. Una historia desde los inicios hasta nuestros días, Barcelona, Herder, 2005. 
Sandra Teresa Álvarez Ledo

Tester, J., Historia de la Astrología occidental, Madrid, Siglo Veintiuno editores, 1990.

Vicente García, L. M., «La astrología en el Libro de Buen Amor. Fuentes y problemas sobre el uso de conceptos astrológicos en la literatura medieval española», Revista de Literatura, 122 (1999), pp. 333-347.

, «Notas sobre la actitud de Juan de Mena hacia la astrología a propósito del libro de Sue Lewis: Astrology and Juan de Mena's Laberinto de Fortuna», Revista de Literatura Medieval, 16 (2004), pp. 297-326.

Estrellas y astrólogos en la literatura medieval española, Madrid, Ediciones del Laberinto, 2006.

Villena, E. de., Obras completas, P. M. Cátedra (ed.), Madrid, Turner, 1994, vol. 1.

ZILli, C., «Dibattito sulla Fortuna nel Cancionero de Baena?», La Nuova Ricerca, 3.3 (1994), pp. 1-50. 